\title{
Monitoring of the Epidemic Situation with Q Fever in the Regions of Ukraine
}

\author{
Olha Zarichna* \\ Rickettsial Infections Laboratory, SI "Lviv Research Institute of Epidemiology and Hygiene of the Ministry of Health of Ukraine", \\ Lviv, Ukraine
}

\section{Objective}

To investigate $\mathrm{Q}$ fever pathogen distribution among ixodic ticks, myomorphic rodents, febrile patients, residents of enzootic areas with $\mathrm{Q}$ fever and persons in contact with Q fever, specifically infected persons in the Southern and Western regions of Ukraine.

\section{Introduction}

Improvement of the $\mathrm{Q}$ fever epizootic and epidemiological surveillance system remains an urgent veterinary service and healthcare problem in Ukraine. The grounds for this should be laid by the results of monitoring studies of persons with a professional infection risk (livestock farms, animal processing enterprises, veterinary specialists, etc.) and living in enzootic territories, as well as research of Q fever pathogen possible sources reservoirs.

\section{Methods}

Real-time PCR - detection of specific DNA segments of Coxiella burnetii with application of commercial reagent kits. Immunofluorescence microscopy - detection of antigens/antibodies of studied rickettsia in biological substrates using luminescent immune sera labeled with fluorescein-5-isothiocyanate. Epidemiological methods - analysis of infectious diseases foci epidemiological maps. Statistical methods - data analysis using such software as Excel and Quantum GIS (1.6.0).

\section{Results}

Primarily, Q fever endemic areas are formed because of the circulation of Coxiella burnetii in warm-blooded animal populations and their blood-sucking ectoparasites, which are the main source of the infection in humans. Based on the aggregated data received from multi-year research projects in Ukraine, Q fever enzootic territories were found in 18 administrative regions, Crimea and the city of Sevastopol. Currently we know of 257 areas where the pathogen was detected. The epidemic process in these territories is manifested by sporadic human diseases and the detection of the pathogen in natural carriers. The possibility of the natural foci epidemic potential increase in these territories is confirmed by the higher titers of $Q$ fever pathogen specific antibodies detected in the local population.

The results of the research of the infected material that was collected in Southern Ukraine during 2014-2016, showed the preservation of the Q fever causative agent in natural foci both in Danube-Dniester interfluve area of Odesa region and in Trans-Dnistrer areas, and its significantly less prevalent in the area adjacent to Odessa. In addition, the signs of natural foci formation have been revealed in other areas, which is indicative of current epidemic activity of natural foci of the infection. The results of serological studies and clinical and epidemiological surveys indicate that in the immunological structure of the population of the Danube-Dniester interfluve areas of Odessa region, Q fever is most common in rural population of working age, especially those constantly contact with farm animals. In the IvanoFrankivsk region, serological studies in 2014 -2016, detected no Q fever seropositive people, indicating the pathogen being in the reserve stage, which corresponds to the inter-epidemic period. At the same time, the detection of $C$. burnetii in ticks in the enzootic territories indicates the possibility of the pre-epidemic process being formed.

Since by pathogen range and transmission mechanisms $Q$ fever in Ukraine is associated with many natural-focal zoonotic infections, it is advisable to monitor endemic areas using a modern observation algorithm using the introduction of geoinformation systems and the molecular genetic characteristics of circulating strains. This will increase the effectiveness of the detection of current natural and anthropurgic foci of such infections, will contribute to their detailed characterization and systematization, improve epidemiological surveillance and prevent the emergence of epidemic outbreaks among the population. The results of the research will contribute to the improvement of differential diagnosis of febrile states with an unclear etiologic agent.

\section{Conclusions}

The results of the Q fever pathogen detection in the material collected in Southern and Western regions of Ukraine showed that the area of prevalence of this agent has been expanded to the areas and settlements that are not included in the list of enzootic territories. Involvement in the ecological cycles of ixodic ticks and mouse-like rodents was observed. The presence of polyvectoral and polyhostal natural foci of this infection was found. The circulation of the causative agent of Q fever in the territories of Odesa and IvanoFrankivsk regions where epidemic outbreaks and sporadic disease in people were also observed.

\section{Keywords}

Coxiella burnetii; Q fever; natural foci; Ixodic ticks; Myomorphic rodents

\section{Acknowledgments}

Authors would like to express their gratitude to the State Institution Odesa Regional Laboratory Center of the Ministry of Health of Ukraine and State Institution Ivano-Frankivsk Regional Laboratory Center of the Ministry of Health of Ukraine.

\section{References}

1. Surveillance Atlas of Infectious Diseases // http://atlas.ecdc.europa.eu/ public/index.aspx.

2. UCDCM Information Sheet as of 07/21/2010 No. 04.4-31/40/868 On Epidemic and Epizootic Situation with Zoonotic Infections Common for Humans and Animals and Methods of their Prevention in Ukraine.

\section{*Olha Zarichna}

E-mail: olha_zar@i.ua 